\title{
A UNIDADE DO DUPLO OLHAR EM MARCELO GRASSMANN
}

Dalila dos Santos Cerqueira Pinto ${ }^{1}$

Maria Luisa Luz Távora ${ }^{2}$

\section{Resumo:}

Um mergulho na obra do gravador Marcelo Grassmann, privilegiando os olhares das fantásticas imagens da sua gravura, foi feito a partir dos estudos sobre o fenômeno da linguagem em Gaston Bachelard e o ato criador da imaginação poética, produzindo imagens de sonho.

Grandes viagens flutuam nas águas dos olhares nos sonhos de Grassmann. Esta olhada de superfície nos traz somente reflexos do exterior. Será preciso ir mais e mais fundo. Como os mergulhadores de pérola, só na angústia da apnéia se desdobrarão as maravilhosas imagens que tão bem se escondem do olhar curioso. No suspiro do quase morrer renascemos em outros olhares. A poesia de Cecília Meirelles e Lya Luft foram brilhantes luzes neste espaço sonhado de devaneios do olhar.

Palavras-chave: Grassmann, Bachelard, criação, imaginação.

\begin{abstract}
:
Using Gaston Bachelard's theories about language as a phenomenon and the creative act spurred by the poetic imagination, we offer a critical appreciation of the work of engraver Marcelo Grassmann, paying special attention to the fantastic, dreamlike images he creates.

An introspective look into Grassmann's dreamscapes reveals wonders similar to the ones uncovered by pearl divers, who must overcome breathing anxieties in order to get a glimpse of wondrous worlds. A near death experience transformed into rebirth. The poetic perspectives of Cecília Meirelles and Lya Luft inspired us to imagine Grassmann's dream spaces.
\end{abstract}

Key words: Grassmann, Bachelard, artistic creation, imaginary.

Um mergulho na obra do gravador Marcelo Grassmann, privilegiando os olhares das fantásticas imagens da sua gravura, foi feito a partir dos estudos sobre o fenômeno da linguagem em Gaston Bachelard e o ato criador da imaginação poética, produzindo imagens de sonho.

Um grande sonhador é Marcelo Grassmann. Sonha o sonho do fantástico, do não existente no cosmos real. Vê com os olhos desses seres que cria, devassa seus interiores e o nosso. Olhos que devoram imagens é o que o artista é. Ver profundamente é para onde ele nos leva.

Começamos na superfície de suas imagens que nos envolvem, para mergulhar e sonharmos nossas profundezas. Não há limites para imaginar! O olhar eterno, dentro e fora, nos habita e nesse acolhimento as visões nunca terminam.

\footnotetext{
1 Instituição: Escola de Belas Artes da Universidade Federal do Rio de Janeiro, Programa de Pós graduação em Artes Visuais. E-mail: dalisan@superig.com.br

2 Instituição: Escola de Belas Artes da Universidade Federal do Rio de Janeiro, Programa de Pós graduação em Artes Visuais. E-mail: marialuisatavora@terra.com.br
} 
................estamos na posição incômoda da dialética do profundo e do grande: do infinitamente reduzido que aprofunda ou do grande que se estende sem limite ${ }^{1}$.

A poesia de Cecília Meirelles e Lya Luft foram brilhantes luzes neste espaço sonhado de devaneios do olhar.

Tudo no mundo é duplo: visível e invisível....2

Para estudar o ato criador da imaginação, seria, sem dúvida, mais razoável nos

dirigirmos às imagens..........que nascem de nosso próprio sonho ${ }^{3}$.

Imagens de grandes viagens flutuam nas águas dos olhares nos sonhos de Grassmann. Esta olhada de superfície nos traz somente reflexos do exterior. Será preciso ir mais e mais fundo. Como os mergulhadores de pérolas, só na angústia da apnéia se desdobrarão as maravilhosas imagens que tão bem se escondem do olhar curioso. No suspiro do quase morrer renascemos em outros olhares. $\mathrm{Na}$ clareza aparente, no brilho cristalino se escondem muito mais que serpentes e monstros que sabem aparecer, uns para assustar, outros, iludir.

O olhar é chama, é fulgor, luz. O fogo do olhar incendeia o reflexo das imagens nas águas. Onde pode o fogo continuar ardendo sem queimar, sem perder sua luz se não no reflexo das águas? Esse espelho que trás em cada lâmina uma nova face desse amigo caloroso que se contempla. $\mathrm{Na}$ tranqüilidade das águas ele se espelha sem temer ser devorado e brilha sem competição pela vida.

Procurei-me nesta água da minha memória

Que povoa todas as distancias da vida

E, onde, como nos campos, se podia semear,talvez

Tanta imagem capaz de ficar florindo.......... ${ }^{4}$

Qual memória, qual matéria fará recordar tempos imemoriais? Que campos nosso olhar percorrerá em lembranças?

Sim, a que tempo, a que memória nos transporta o sonho diante desses fogos que cavam o passado como "cavam a cinza"?

Grassmann nos leva a espaços-campo de imagens primeiras, primitivas imagens que em nos trabalham num aquém mundo. Seus olhares imemoriais nos levam ao fantástico, ao anterior do vivido.

Fenômenos do olhar são faíscas, raios iluminando o instante poético. A pupila se dilata, a procurar cores, luzes de devaneios.

Quando esses traços de fogo, raio ou vôo, vem nos surpreender em nossa contemplação, eles aparecem a nossos olhos como instantes ampliados, eles são instantes de universo ${ }^{5}$.

No universo do artista quantos mundos habitarão? Todos os eus mais profundos, obscuros, sublimados, camadas interiores. Quantas viagens nos levarão a imagens inacreditáveis. Quantos seres, somos?.

Só há o tempo suspenso, só o momento, o instante em que me metamorfoseio em outros, porque me penso contrários.

Cerro os olhos para ver melhor, subjetivar fenômenos para os quais já não servem as explicações. Busco ser amplo, encharcar o todo com as águas da memória. Deixo fluir o que vem de fontes tão profundas. Olho o duplo e o outro que vivem juntos em mim e sendo luz no olhar imemorial, olho no espelho onde o que se vê não é, e já não sei quem me sonho. 


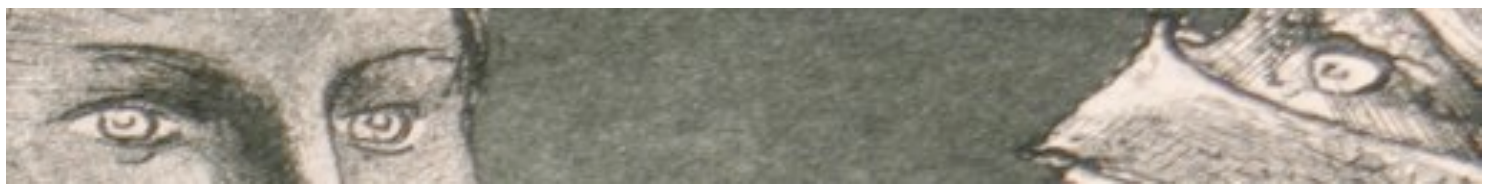

São os espelhos que me revelam

Sem eles eu talvez não soubesse de $\operatorname{mim}^{6}$

O olhar imaginante quer sonhar tanto nas luzes acompanhadas de calor, como nos fogos fátuos. Tanto na superfície, no exterior, como no interior mais profundo e ser "a um tempo, esplendor e sepultura", 7 como sonhou o poeta. Não se reconhecer no oposto, mas sentir imensa gratidão por ele ser, como clarão, relâmpago iluminando outras duplas faces.

Um olhar primeiro sempre nos trará o olhar significado, objetivo, inquieto. Quem? $\mathrm{O}$ que? Por que? Quando? Fujo dessa primeira visão exterior e busco com as luzes do sonho, ora entrevendo, ora não, o tão sonhado. Navego nesta barca/berço onde o tempo é suspenso no descontínuo ir e vir e as imagens inacreditáveis flutuam como em águas transparentes, refletindo, espelhando, desdobrando estas mesmas imagens em paisagens pintadas na profundidade das águas, como nas águas do olhar.

O tempo não existe. Sou apenas

O aqui e o presente, e o atrás disso,

Como um rio que corre, mas não passa

Pois ele é sempre, em mim, agora ${ }^{8}$

$\mathrm{Na}$ pupila as luzes me atravessam, me fazem morrer e renascer em outros olhares. O poeta sonha o sonho de renovação.

Renova-te

Renasce em ti mesmo

Multiplica os teus olhos, para verem mais

Multiplica os teus braços, para semeares tudo

Transformação, metamorfose, sou eu e outro no um.

Destrói os olhos que tiverem visto

Cria centro, para as visões novas

Destrói os braços que tiverem semeado,

Para se esquecerem de colher

Renasce em novos olhares para que a coragem da renovação dê ritmo ao que repousa e ao que renasce. Renova o ser múltiplo em uma chama nova.

Sê sempre o mesmo

Sempre outro.............. ${ }^{9}$

Com a imaginação autônoma, sem ligação com a realidade, o artista nos arrebata e surpresos vemos surgir ao nosso olhar, seres e espaços desconhecidos. Espantados, nesse outro meio, saboreamos o gosto infinito de respostas, vivendo entre tempos, frestas, para nesse olhar eterno e sem limites viver em duplo, o maravilhamento de olhar o mundo e ser olhado.

Descer a correnteza da memória suavemente, deslizando nessa imensidão, buscando no mais profundo abissal, olhares que lambem o espaço interior. Se ver não significa pré ver o personagem com que o sonho nos brinda. Ele surge do instante, do inesperado, a imagem como um fantasma rebelde atravessando o ser poético. E por que não se deixar sonhar no reino da imaginação poética?

No sonho do sonhador o menor valor se multiplica e se transforma. Múltiplo na unidade, no renascimento de um novo olhar, sou o um e o todo. 


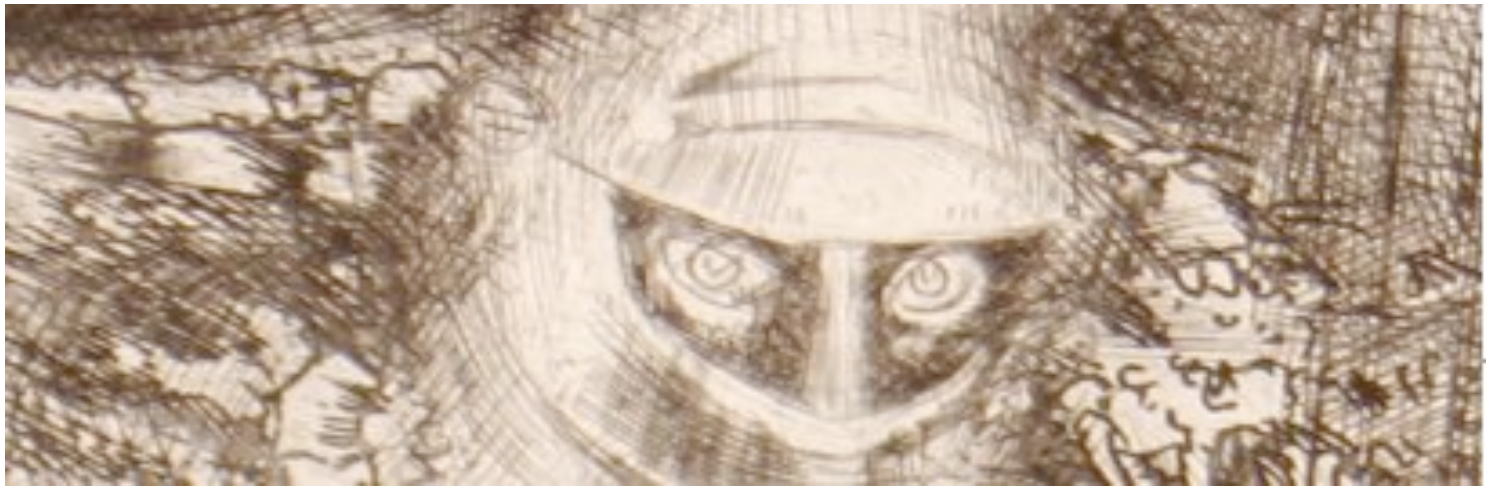

Ser liberto em duplo é no duplo olhar que o todo se completa. Dentro de mim as faíscas se cruzam, iluminam a escuridão, espelham e retornam e já navego por outras paisagens com o meu ver. Na correnteza de palavras navegam sonhos infinitos. Em uma única história, um universo sem limites. Pelas minhas águas se espelham e flutuam, os fogos do olhar.

\section{Notas Bibliográficas}

1. BACHELARD, G. - A Poética do Espaço - Editora Martins Fontes - São Paulo - SP, 1993

2. MEIRELLES, C - Olhinhos de Gato - Poesia Completa - Nova Aguillar Editora, São Paulo-SP, 1994

3. BACHELARD, G. - A Poética do Devaneio - Editora Martins Fontes - São Paulo SP, 2001

4. MEIRELLES, C. - Medida da Significação - Poesia Completa - Nova Aguillar Editora, São Paulo-SP, 1994.

5. BACHELARD, G. - Fragmentos de uma Poética do Fogo- Editora Brasiliense, São Paulo-SP, 1990 .

6. MEIRELLES, C - Personagem - Poesia Completa - Nova Aguillar Editora, São PauloSP, 1994.

7. BILAC, O. Língua portuguesa - Poesias. Livraria Francisco Alves, RJ, 1964.

8. LUFT, L. - Para não dizer Adeus - Poema "O Rio do Tempo" - Editora Record Rio de Janeiro-RJ, 2005.

9. MEIRELLES, C - Cânticos - Editora Moderna, São Paulo-SP, 1982. 